\title{
"All for One and One for All"- Creating a Mobile Learning Net for ESP Students' Needs
}

\author{
https://doi.org/10.3991/ijet.v12i04.6428 \\ Marianthi A. Batsila \\ Open University of the U.K. \\ marbatsila@gmail.com \\ Charilaos A. Tsihouridis \\ University of Thessaly, Volos, Greece \\ hatsihoureuth.gr \\ Anastasios H. Tsihouridis \\ Democritus University of Thrace, Komotini, Greece \\ tsabtsih@gmail.com
}

\begin{abstract}
This paper looks into the ways ESP teachers have employed mobile learning scenarios in the teaching of English to Vocational Secondary school learners. Six teachers and 157 students participated in the research. Questionnaires and focus group discussions addressed to the students and semistructured interviews with the teachers were the research tools. The thematic analysis of the interviews revealed that teachers use mobile learning as a mode of instruction to minimize distance, fill learning gaps due to student absences, enhance the learners' ESP level and activate the weak or shy ones. The focus group discussions, thematically analyzed, and questionnaire answers, analyzed with the SPSS statistical package, have shown that students consider this mode of learning easy, interesting and useful. According to the results students' gender does not affect their decision except that of the appropriateness of the method whereas their age and working status affect certain answers with older working students' opinion outbalancing the younger non working students' views on the method.
\end{abstract}

Keywords-Vocational Education, Mobile learning, English for Specific Purposes, Instructive scenarios

\section{Introduction}

We are living in an era of a continuous and never-ending wind of change owing to the increasing pace of technology which affects our present reality. Due to this technology advancement new tools and inventions have emerged offering us a vast source of information, ideas and solutions to confront a variety of issues that concern all aspects of our lives. This tremendous change has especially affected the new generation turning it into the ICT experts of today, surprisingly enough, to a much greater 
extent than adults and their own teachers perhaps ever could be. In this state-of-the art technology world, ICTs and their integration in the teaching and learning process have managed to turn education into an interesting process, often converting it into a game, and thus motivating learners and enhancing their skills level $[1,2,3,4,5,6]$. Over the past years many educators, scholars and researchers' aim has been to investigate whether a wide variety of constantly emerging devices and ICT applications can prove to be beneficial for the classroom $[7,8,9,10]$.

Especially for the teaching of English and particularly English for Specific Purposes (E.S.P.), ICTs have been found to serve as significant tools for teaching and learning purposes. E.S.P. refers to a language program which is designed for a specific reason and needs of the person who is learning English [11]. Vocational schools comprise E.S.P. courses in their curricula and this is because English and particularly specialized English is considered a major qualification for professional purposes. To this end, Vocational School learners are trained accordingly in order to prepare for their future English language demands in the employment market. Consequently, Vocational school teachers need to be inventive, innovative and adequately trained in order to provide their learners with such material and methods that will help them respond successfully to the needs of their future profession. Within the framework of ICTs, mobile devices and apps are those that have augmented considerably lately and their use has expanded to a great extent especially among young learners [12]. This is due to the portability and easiness of their use, accessibility of apps and their capability to download without major difficulties. Furthermore, many of the mobile apps are found gratis, just by surfing on the net and provide learners with an extensive variety of uses for personal, social, academic or professional reasons.

Recently, mobile devices have been employed for mobile learning (m-learning) defined as "Any activity that allows individuals to be more productive when consuming, interacting with, or creating information, mediated through a compact digital portable device that the individual carries on a regular basis, has reliable connectivity, and fits in a pocket or purse" [13]. Mobile learning can be achieved anywhere and anytime. What one simply needs to do is to have access to a mobile device with internet connection or a device with operations that resemble computers with various applications and uses. Such devices are mobile and smart phones, net books, tablets and i-pads, Media players (podcasting and videos), games consoles or e-book readers for instance. Research shows that mobile learning has been effective in teaching, [14], developing learners' linguistic and communicative skills [15], "addressing a number of educational problems" [16], capable to introduce innovations in pedagogy [17].Linked to the above, a significant issue which emerges in today's classrooms and strongly concerns educators is the so called mixed ability classes. These classes appear due to the diversity of the student population, their different cultural and cognitive background, needs, skills, age and abilities. Therefore, it seems urgent for teachers to employ a variety of differentiated tools and methods in their teaching in order to address all students' needs [18]. 


\section{Rationale for the Present Study}

Diversified classes are a usual phenomenon in schools today like in Vocational Schools in Greece, because learners derive from a big variety of places when they come to attend lessons. In Greece, Vocational schools are usually two or three per city with a population of 150.000 compared to General High Schools that may reach a number of 15 and more institutions in a city. This results into much differentiated Vocational school student communities who appear to have a varying cognitive level. This is depicted on lack of equal opportunities as learners that live in cities have the ability for private extra lessons whereas this is not the case for learners that come from the suburbs or villages due to absence of private schools. Therefore, it seems urgent for teachers to employ differentiated instruction [the process of "tailoring instruction to meet individual needs" making it "a successful approach to instruction", [19] in order to address all students' needs. What is more, a big percentage of these Vocational school learners work after their school hours either to make a living or to train and practice for their future working skills. To this end, it is a frequent phenomenon to see them miss classes because they are tired or have an unexpected working duty to attend to. To remedy the problem, teachers employ a variety of instructive ways among which mobile learning. Driven by the aforementioned points and out of curiosity to discover teachers' practices, the authors of this paper decided to investigate why and how teachers do this and how mobile learning is perceived by their students.

\section{The Research}

\subsection{Research questions}

The research employed qualitative and quantitative approaches to explore teachers' and learners' opinion on mobile learning. The research questions were the following: 1.Why do teachers employ mobile learning practices? 2. How do they apply mobile learning in their teaching? 3. What do teachers think of the mobile learning approach? 4. What do learners think of the mobile mode of learning and how do factors such as gender, age and work affect their decision?

\subsection{The Sample}

The participants were six randomly selected Vocational Secondary School teachers and their randomly selected 157 students. All participants derived from six Vocational schools in the research area. Their profile is as follows:

The teachers: All six participant teachers (female) had a working experience that ranged between eight to twenty one years in both general and vocational schools. Additionally, they had all taught ESP courses of various specialisms (i.e. accounting, refrigeration, tourism or electronics) for a school period between five to nineteen years. All the teachers had received ICT training at seminars held by the government 
in relation to the use of ICT -Web 2.0 tools for teaching purposes. Upon the explanation of the aims of this research to the teachers and their consent to their participation, interviews took place in places and time of their choice to help them feel comfortable and relaxed. Five interviews took place in the school libraries, during the teachers' school timetable hourly breaks. The sixth interview was held in the teacher's classroom in theend of the school day. All teachers were explained that they could withdraw any time they wished and that they could receive a copy of the transcript if they wanted. Their names are not mentioned in this paper for ethical reasons. Instead, they are referred to as T1 (teacher one), T2 (teacher two) for instance, so as to be anonymous.

The students: The participant students were 157 and they all attended the last grade of Vocational Secondary Schools and studied a variety of subjects (mechanical engineering, accounting, refrigeration, tourism agency, computing). The students were between 17 to 20 years of age as young people up totwenty years old may also attend Vocational schools by law. All learners of the third grade of these schools are taught ESP courses, for every specialism and for two hours per week. All students were informed that they would take part in this research and were explained its aim. For the focus group discussions the adult students consented for themselves whereas for the underage learners their parents' consent was received. For ethical reasons, pseudonyms are used in the students' answers in the results section of this research.

\subsection{Research tools}

This research employed quantitative and qualitative research methods in order to receive possible answers for the research questions [20]. In particular, for the purposes of the first three questions, semi-structured interviews were conducted with the participant teachers. This method was considered to be most appropriate as our aim was not numerical facts but the teachers' in-depth thoughts of the research issues and their views and opinion with as many details as possible. Furthermore, it was thought as being an appropriate method to ask teachers describe the ways they used mobile learning scenarios in their teaching. For the fourth research question, both quantitative and qualitative research methods were used. Specifically, a questionnaire was administered to all learners as questionnaires are considered less time consuming, and more appropriate for bigger samples [20]. Additionally, two focus group discussions were conducted with two groups of 22 and 19 learners (derived from the total amount of 157) respectively, randomly selected, so as to receive more profound answers in relation to their opinion about mobile learning as a learning process. For the two focus group discussions to take place, the students', parents' and principals' consents were asked and received. Although more students were approached initially (68 students from all six schools, randomly selected) only 51 of them (underage students' parents or adult students) consented to their participation. The students were decided to be randomly divided into two groups (22 and 19). The two groups derived from all six schools so as to have as a representative sample as possible, for the purposes of the third research question. The two discussions took place the same day in the school library of one of the six participant schools, which was commonly decided by the six 
participant teachers. For validity purposes all tools (interviews, questionnaire andfocus group discussion questions) were piloted with two teachers (the interviews), 15 learners (the questionnaires) and seven learners (focus group discussions) for appropriacy of the wording, coherence and understanding of the questions. The data taken were used to modify, redesign and reformulate the final versions of all the tools.

\subsection{Structure and analysis method of the interviews}

For the validity of this research tool the questions were piloted with two teachers and were designed following interview design principles [20]. The interviews lasted between 22 to 34 minutes and this depended on the participants' profile as some of them were rather reserved while others were more extrovert people. The basic questions of the interviews were classified into 4 groups: 1. Participants' working profile, 2. Reasons to use mobile devices for teaching and learning purposes, 4 . Ways mobile devices are used for teaching 5 . The effect mobile learning has on learners' skills competence. For the analysis of the interviews the "content analysis" method was employed. After the transcription, the repeated listening and reading of the interviews content, the most significant parts that linked to the research questions were isolated and recorded and the data analysis units/key words were determined. The key words were "mobile devices", "interesting", "motivating", "difficult", "easy", "helpful", "needs", "level", "competence", "vocabulary", "reading skills", "listening skills", "writing skills", "speaking skills" that were included in the participants" answers, in relation to the aims of the research and research questions. Due to the large body of information, all data was classified in groups, based on which the content analysis took place.

\subsection{Structure and analysis method of the questionnaire}

Similarly, for the validity of this tool, the questions were piloted with fifteen learners and were based on questionnaire design principles [20]. The questions were semistructured and answers were asked to be given on a five point Likert scale (Strongly agree, agree, neutral, disagree, strongly disagree). The questions investigated issues such as the extent to which the mobile devices were found to be an interesting, motivating, useful, appropriate, innovative, helpful and leading to skills improvement method of learning. The analysis of the answers was carried out with the use of the SPSS statistical package. The aim of the questionnaire was also to detect whether factors such students' gender, age and working status affect their decision. The questionnaire taking was followed by informal short discussions with randomly selected learners in order to shed more light into their answers.

\subsection{Structure and analysis method of the focus group discussions}

For the validity of this last tool the questions were piloted with seven learners and were designed following the same process and principles that was followed for the teachers' interviews. The two focus group discussions ranged between 27 to 31 
minutes. The questions weresemi-structured and they were classified into 4 groups: 1 . Usefulness of the method, 2. Easiness of use of the method/accessibility, 4. Advantages of the method/positive points 5. Disadvantages of the method/negative points. For the analysis of the discussions the "content analysis" method was employed. The key words here were "useful", "accessible", "difficult", "easy", "helpful", "positive", "negative" that were included in the students' answers, in relation to the aims of the research questions.

\section{$4 \quad$ Results}

\subsection{Research question one: Reasons to use mobile devices for teaching E.S.P. classes}

Based on teachers' answers, mobile devices are used for teaching purposes for a number of reasons. As teachers claimed one reason is the linguistic diversity of their classes, which leads to the need of personalized learning. According to the teachers their students are mainly mixed ability classes. Therefore their level of English varies and it is difficult for them to employ one single method or tool to teach. Another reason is the difficulty of access to school of some learners who live in rather remote villages. As the teachers revealed these learners do not always manage to come to school on a daily basis due to a problematic traffic network of buses, bad weather conditions or unexpected family obligations (need to contribute to family businesses, usually of similar activities to their studies - electricians/refrigerants/computer operators etc) or as part of some sort of their family business training. This leads to absences from school and consequently their staying behind in courses. However, almost half of the teachers admitted they used mobile devices for teaching purposes out of their wish to experiment and try new ideas and methods. Based on their answers, a variety of tools keeps their learners motivated towards learning. Therefore, they are not easily bored and this helps them accomplish their teaching goals to a greater extent. Moreover, they themselves are also curious to explore something new and see how it works with their students. Their words are depicted in the following extracts: "I have a lot [learners] from villages around school... they work with their parents... to help them in their firm ... and many... cannot ... do not come to school every day... it's not negotiable... I tried..." T3, "When the weather is bad, especially in the winter time, it takes a lot of time for the bus to get up there... and come back... we understand... but they miss classes, we can't do much about it..." T4, "I have a couple [learners] that are B2 level but the majority is A2 or B1... I need to give them more material to work on ...to expand what they know, the hours are not enough.... the hours we teach I mean..." T6, "I like to experiment and do new things. It keeps me going... they like it too; they want to find out what it is..." $\mathrm{T} 1$. 


\subsection{Research question two: Exploitation of mobile devices for teaching- instructive scenarios}

The teachers who took part in this research used ICT as teaching tools in order to design activities and instructivescenarios for their learners aiming at learners' access to them through their mobile devices. They based this choice on the fact that almost all their learners had smart phones or tablets and therefore it was easy to employ them for instructional purposes. Thus, they used them to supplement the syllabus of the specialty courses and enrich its content where needed. Furthermore, they tried to keep their learners' interest quite high, motivating them to use English and assisting them with their duties, especially those who worked in parallel to their school studies. This initiative was the particular teachers' voluntary decision that came after having been trained in the use of Web 2.0 tools. The teachers expanded this idea by uploading the material not only on their school site or platform of their choice but also on a common school site, aiming to create a net for all students of all schools to visit and advise the material. The following scenarios are teachers' suggestions for mobile learning. Each scenario corresponds to each participant:

Scenario 1: "Expanding on vocabulary for car mechanics": T1 designed this scenario aiming at learners' vocabulary improvement. The scenario comprised three units and four teaching hours each. During each lesson the teacher recorded the vocabulary expressions, phrases and words discussed in the classroom. Students worked in the lab with the help of online dictionaries. They worked on manuals of a variety of cars equipment in the Greek language and attempted to find the equivalent words in English. Students formed groups of three where they cooperated in order to find the translation, form sample sentences in order to apply the new words and present specific parts of a car displaying each equipment in class and talking about it in English. The presentations were video-taped, while students were also asked to form a dictionary of their own with all the words found. The whole material was uploaded in the school website and with the help of Edmodo the students could have access to it and also interact with the teacher and other students when needed. The activity mainly addressed students who were unable for specific reasons to be present in the lesson on a daily basis or those who needed specialized information while working in the afternoons. The students used their tablets or smart phones to have access to this material at the time they wished and for the purposes needed.

Scenario 2: "Filling in tax forms for accountants": This activity was designed by T2. Her purpose was to help her learners in the accounting course to practice filling in tax forms. The scenario was completed within two units and four teaching hours respectively with students forming groups of four to implement the activities. As a number of her learners worked at firms in the afternoons they needed to have a good knowledge of the procedure of tax filling forms as it is quite a complicated process with many particularities. After the teacher had displayed the steps of tax filling she asked the learners to do the same in class assisting their effort. This took four teaching hours for learners to get accustomed toevery detail. Upon completion of this stage a simulation process followed where the class was divided in groups of two and one student was the client and the other was the accountant who was going to help 
her/him fill in her/his tax form. For the consolidation of the skill the teacher videotaped the simulation game and together with small videos she created showing the process of tax filling of forms (podcasting) she uploaded the material on a googles group with access only for her class for those who wanted to repeat the process or use it for their part-time working purposes. Students could have access to it using their smart phones or tablets any time they wished and could also exchange questions with the teacher at real time through mails through their mobiles.

Scenario 3: "Instructions for refrigerants on the use of electrical appliances": Teacher 3 designed this scenario for a small class of 8 learners 7 of which were adults (19-21) and in the afternoons they worked in a variety of companies and/or department stores that sold electrical appliances and in posts such as salesmen or warehouse clerks. They mainly attended the morning Vocational classes in order to enrich their curriculum vitae and expand on specialized knowledge of their speciality as they had already graduated from a Senior High School. According to the teacher the students had difficulty in their writing and speaking skills and in order to focus on them she designed a scenario comprising of four units and four teaching hours each. The activities emphasized instructions on how to use an appliance and how to ask for more information or technical guidance through mails to the production companies. The teacher used power points to explain the linguistic functions used in instructions for pre/while and post writing and speaking activities. Each power point with all the necessary information (grammar, expressions, vocabulary) was uploaded on the school website to be accessible by learners. She also used skype with her learners to strengthen their speaking skills by giving them tips of advice every time a student needed help at his word (they were all young men). All students had access to this material through their smart phones as this medium was the fastest and easiest for them according to the teacher.

Scenario 4: "Preparing a report for computing employees": This scenario was designed for a group of computing class learners. The target was to train them into writing a diagnostic report regarding problems that appear with computers and forward them to the technicians for a solution. The scenario was implemented in three units of four teaching hours each. The lessons were all conducted in the school lab. At the first unit learners were taught how to recognize a variety of reports (for$\mathrm{mal} /$ informal/different recipients) and were emphasized the language, grammar functions and special vocabulary used. The second unit asked learners to write reports of their own based on a variety of problems that the students had seen after a visit to a computingcompany and the department of service. The problems were classified, were copied on a card and each learner was assigned a number of cards to write a report about the certain problem. The report was sent to the teacher's mail who corrected their output. The cards and the corrected reports of the learners (typewritten by the teacher) along with instructions of how to write a report were uploaded on the school website for learners to advise when needed through their smart phones. This way the learners that missed lessons were able to familiarize themselves with the material whereas the student employees had a good guide to their own work.

Scenario 5: "Authentication - an easy process for insurance agents": This scenario was mainly based on real incidents which served as models for the students of 
the mechanics Vocational course. The scenario took two units of four teaching hours and focused on how to form an opinion as an expert regarding damages caused by a car accident. During the first two hours of the first unit the learners studied pictures and watched videos of damaged cars at garages or insurance agencies. The English teacher in cooperation with the mechanics teacher helped the learners identify a variety of problems and record them in their notebooks. This however was done in Greek. During the third and fourth hours of the first unit the students were asked to translate their texts into English with instructions about how to do so when addressing a different recipient (an insurance agency, a client herself/himself, a car mechanic or the police department). The second unit was about their presence in an actual authentication of a car damage so as to form an opinion of their own. During the first two hours the students recorded their notes and were asked to draw their conclusions. In the third and fourth hours they presented their work to an invited insurance agent who gave them valuable feedback with the help of their English teacher. Pictures and videos of the damaged cars together with the recognition and recording of the problems were all uploaded on the school website for any learner to have access to it through their mobile devices.

Scenario 6: "Helping a salesman to follow directions": T6 implemented a scenario for electricians in two successive units of three hours each. Her purpose was to train them into reading directions to a certain place from google earth or GPS. The first three lessons took place in the school computer lab. During the first unit the learners were given certain destinations and were asked to look for the address and the directions on google earth. They were then asked to record the distance and time on their notebooks and find alternative routes via different transport media (walking/car/bicycle/bus). During the second unit the students worked outside school. They were divided in groups and were asked to find the directions and all possible routes to certain destinations. When this was done each group was asked to follow their preferred route to the assigned destination and record the differences between what they had studied and the actual route they had taken. To implement the activity they wereasked to use the GPS in their smart phones or tablets. The whole concept was how to approach a possible client in the shortest and soonest possible route. The idea behind it was to have time to see as many clients as possible and sell as many products as possible to them. The instructions on how to follow google earth along with the students' tasks were uploaded on the moodle platform for the students to have access any time available to them.

\subsection{Research question three: Teachers' opinion on mobile learning}

According to the teachers the scenarios worked really well for a number of reasons. Firstly, the students felt very enthusiastic with the idea of participating on something they could have access later and would form part of it (videos/tasks/recordings). The whole process was found to be very motivating not only for those who participated in the lessons but also for those who could watch the material at their own pace, space and time. According to the teachers' answers the adult students who used the material at their work were very enthusiastic though quite puzzled at first due to the fact that 
they had never done something like that before. As these students admitted to the teachers they felt very confident advising the material instead of looking on the internet or simply asking colleagues or their managers for help. Secondly, the material was found to be useful not only for linguistic purposes but also for the teachers of the specialties (mechanics/accountants) who used it themselves to teach their students online, regardless of its English language content. As one of the teachers admitted she felt she made a "new beginning" or a "change of mentality" towards teaching in her school as her colleagues expressed their wish to work together in order to design similar scenarios for supportive online learning. However they also admitted that there were also some colleagues (though few) that accused them of "playing" with the students instead of really teaching them. They also had to confess that it was not always easy to video tape lessons as it is necessary to take parents' authorities for underage students. However, due to the fact that many of the learners were adults and the teachers had a very good relationship with the majority of the parents they found little difficulty in doing it. Last, and based on the teachers' answers the most important thing was the fact that those learners that had a low level or were quite shy to ask questions in class they could watch the material as many times as needed and could have an online interaction with the teacher eliminating the fear of being ridiculed by their classmates.

\subsection{Questionnaire results -students' opinion}

1. Mobile learning as an easy process: The majority of the learners $(76,43 \%)$ agreed that it is easy whereas $10,83 \%$ strongly agreed, with $8,9 \%$ being neutral about it, $1.91 \%$ (see Fig 1).

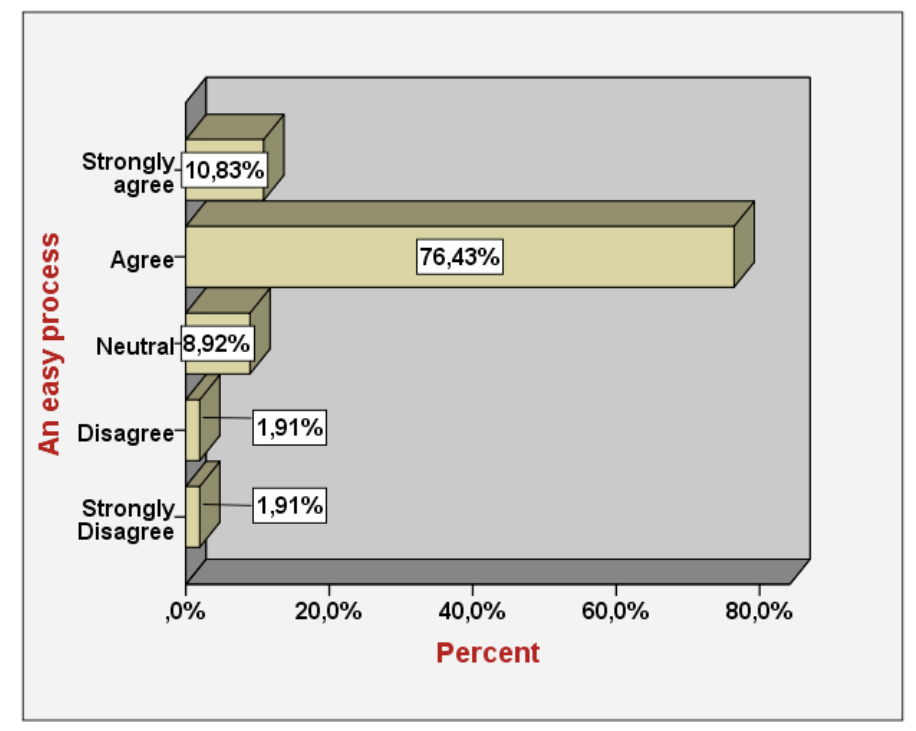

Fig. 1. Is mobile learning an easy process? 
2. Mobile learning as an innovative process: The majority of the learners $(83,44 \%)$ strongly agreed that it is innovative whereas $7,64 \%$ agreed with $6,10 \%$ being neutral about it, 3,18\% disagreeing and 0,64\% strongly disagreeing ( see Fig. 2).

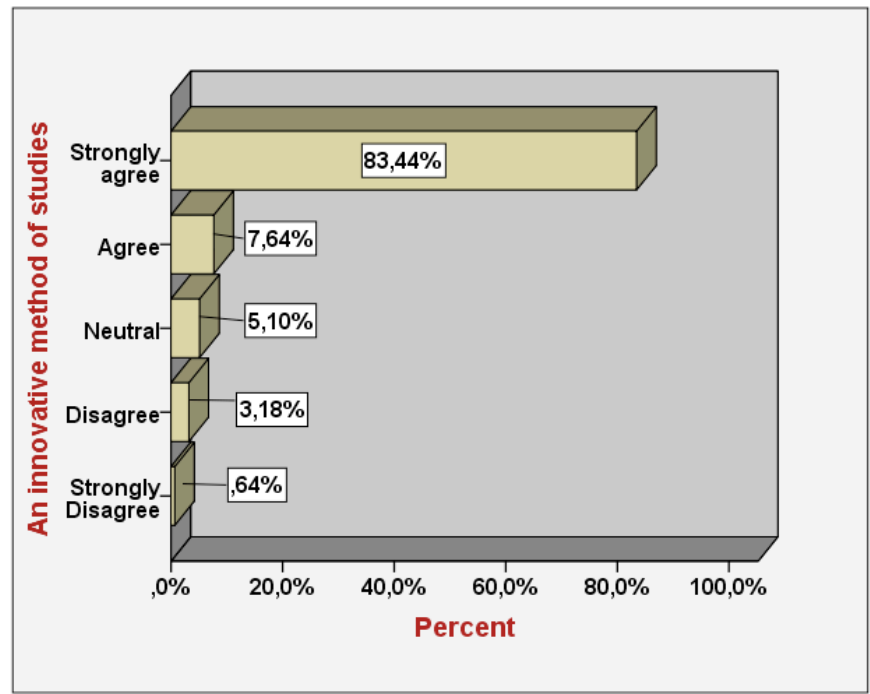

Fig. 2. Is mobile learning an innovative process?

3. Mobile learning as an interesting process: The majority of the learners $(77,71 \%)$ agreed that it is interesting whereas $8,28 \%$ strongly agreed with $10,83 \%$ being neutral about it, $1.91 \%$ disagreeing and $1.27 \%$ strongly disagreeing ( see Fig. 3 ).

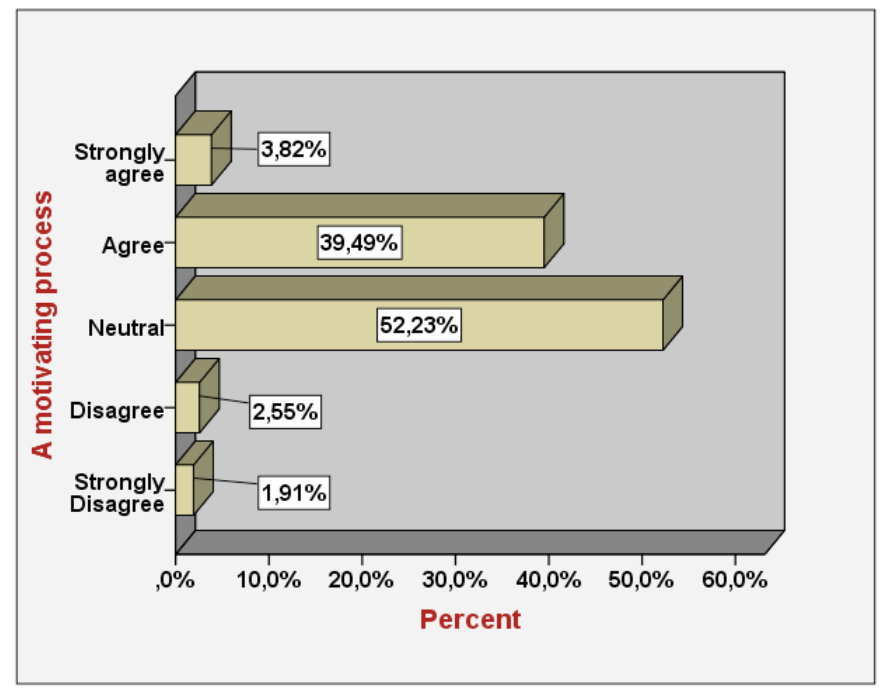

Fig. 3. Is mobile learning an interesting process? 
4. Mobile learning as a motivating process: The majority of the learners $(52,23 \%)$ were neutral about it whereas 39,49\% agreed with 3,82\% strongly agreeing, 2,55\% disagreeing and 1,91\% strongly disagreeing (see Fig.4).

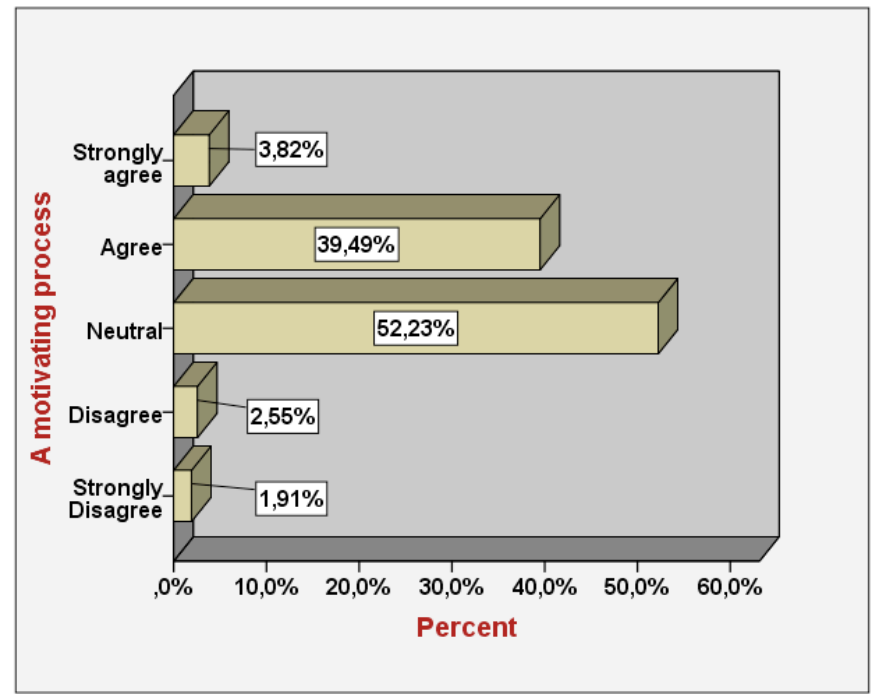

Fig. 4. Is mobile learning a motivating process?

5. Mobile learning as a useful method: The majority $(71,97 \%)$ agreed that it is useful, $14,01 \%$ strongly agreed with $7,64 \%$ being neutral about it, 3,82\%disagreeing and $2,55 \%$ strongly disagreeing (see Fig 5).

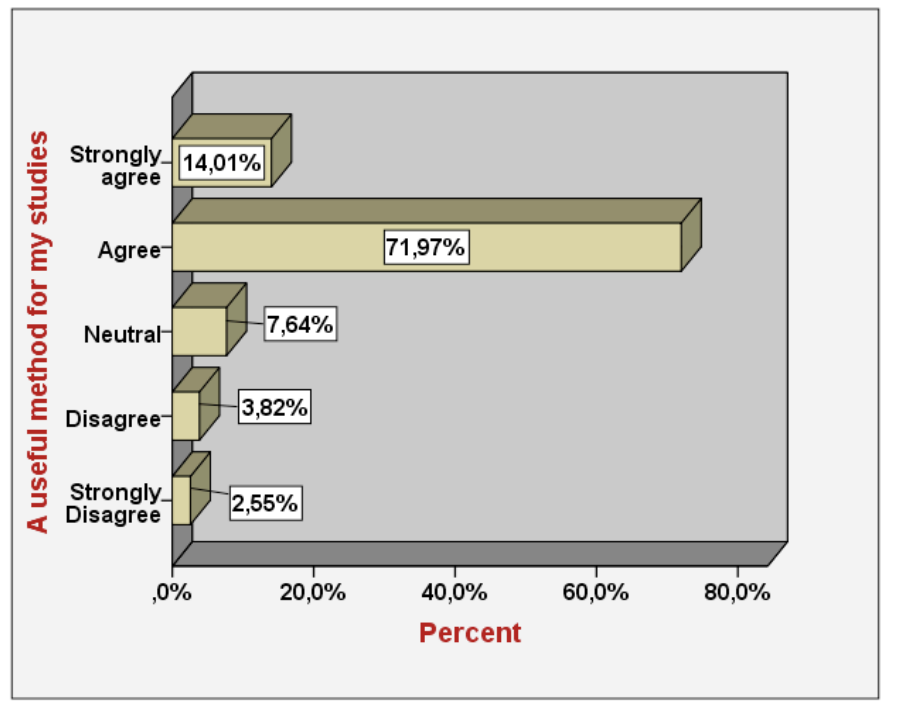

Fig. 5. Is mobile learning a useful method? 
6. Mobile learning as an appropriate method: The majority of the learners $(56,05 \%)$ were neutral about it whereas $27,39 \%$ agreed with $5,73 \%$ strongly agreeing, $7,64 \%$ disagreeing and 3,18\% strongly disagreeing (see Fig.6).

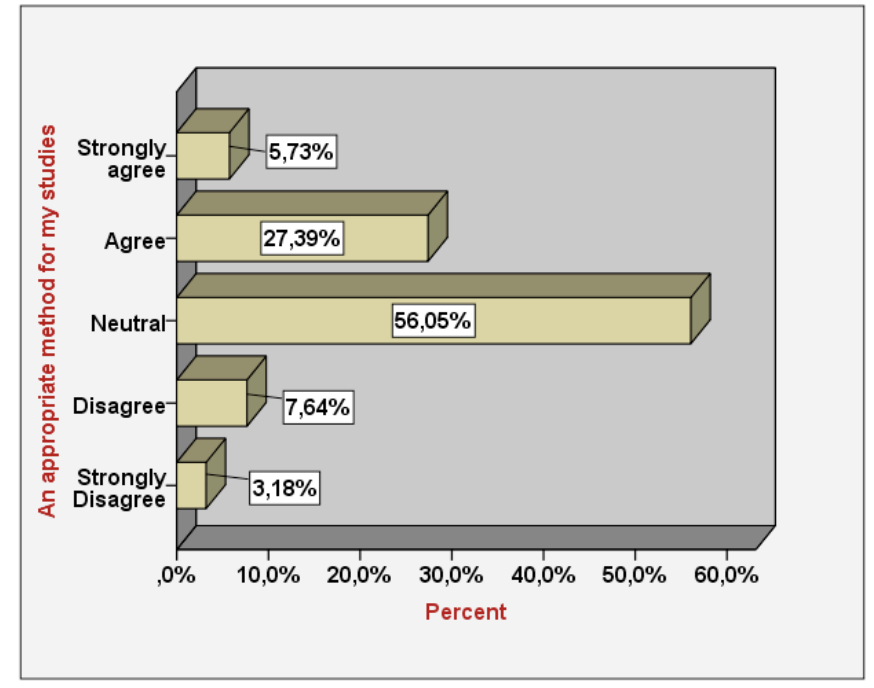

Fig. 6. Is mobile learning an appropriate method?

7. Mobile learning as improving vocabulary: The majority of the learners $(88,54 \%)$ strongly agreed whereas $6,37 \%$ agreed with $3,18 \%$ being neutral about it, $1,27 \%$ disagreeing and 0,64\% strongly disagreeing (see Fig.7).

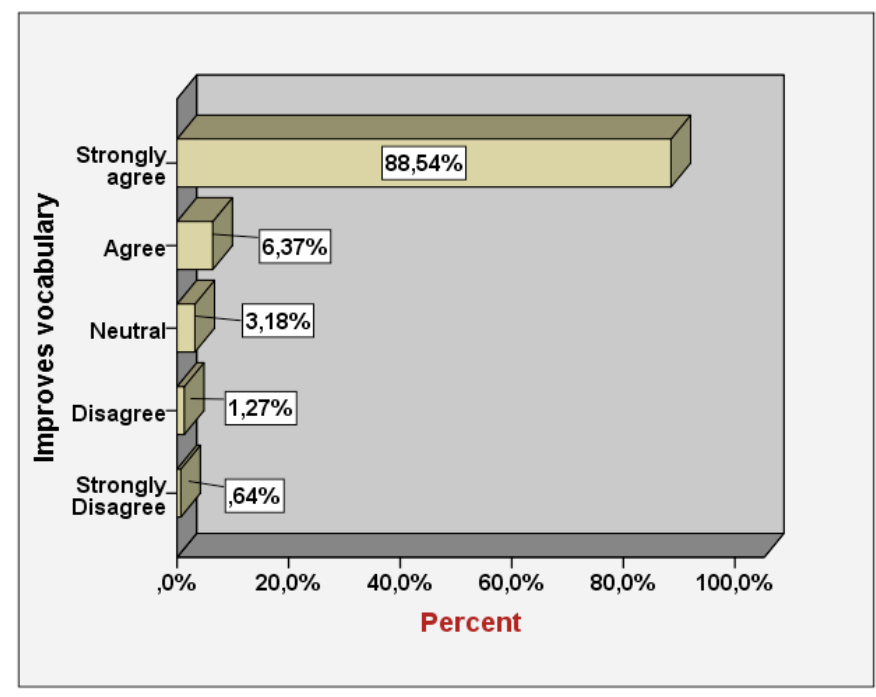

Fig. 7. Does mobile learning improve vocabulary? 
8. Mobile learning as improving reading skills: The majority of the learners $(84,08 \%)$ agreed whereas $6,37 \%$ strongly agreed with $6,37 \%$ being neutral about it, $1,91 \%$ disagreeing and $1,27 \%$ strongly disagreeing (see Fig. 8 ).

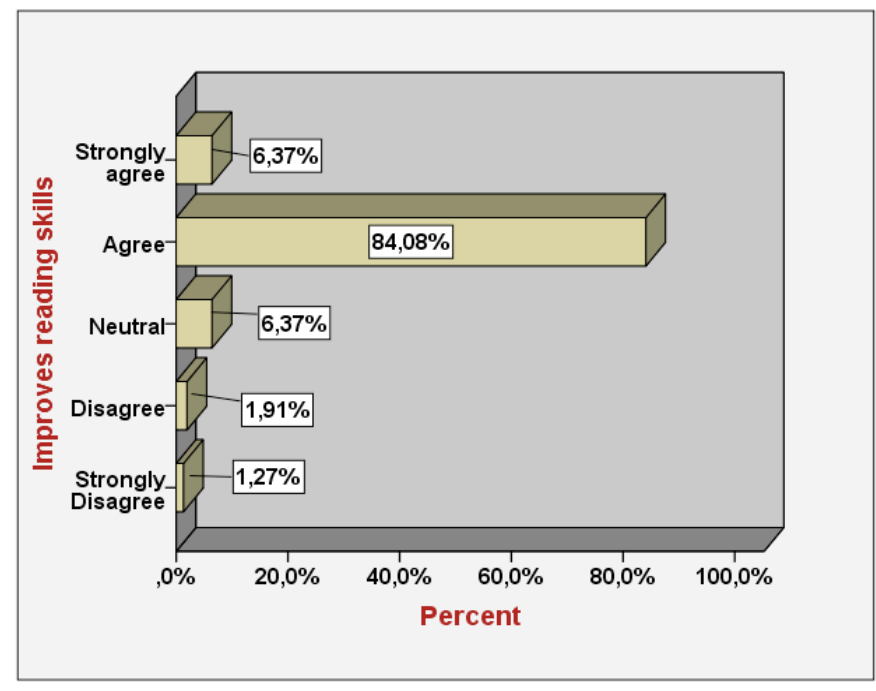

Fig. 8. Does mobile learning improve reading skills?

9. Mobile learning as improving writing skills: The majority of the learners $(65,61 \%)$ were neutral about it whereas $10,19 \%$ agreed with $7,01 \%$ strongly agreeing, $12,74 \%$ disagreeing, and $4,46 \%$ strongly disagreeing (see Fig.9).

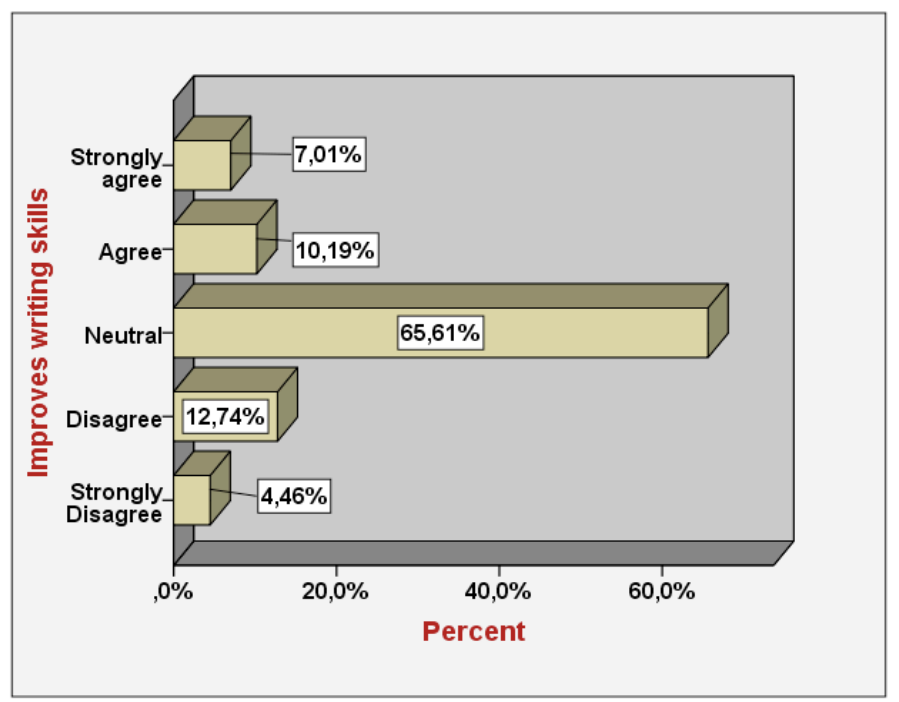

Fig. 9. Does mobile learning improve writing skills? 
10. Mobile learning as improving listening skills: The majority of the learners $(71,34 \%)$ agreed whereas $7,64 \%$ strongly agreed with $9,55 \%$ being neutral about it, $6,37 \%$ disagreeing and 5,10\% strongly disagreeing (Fig.10).

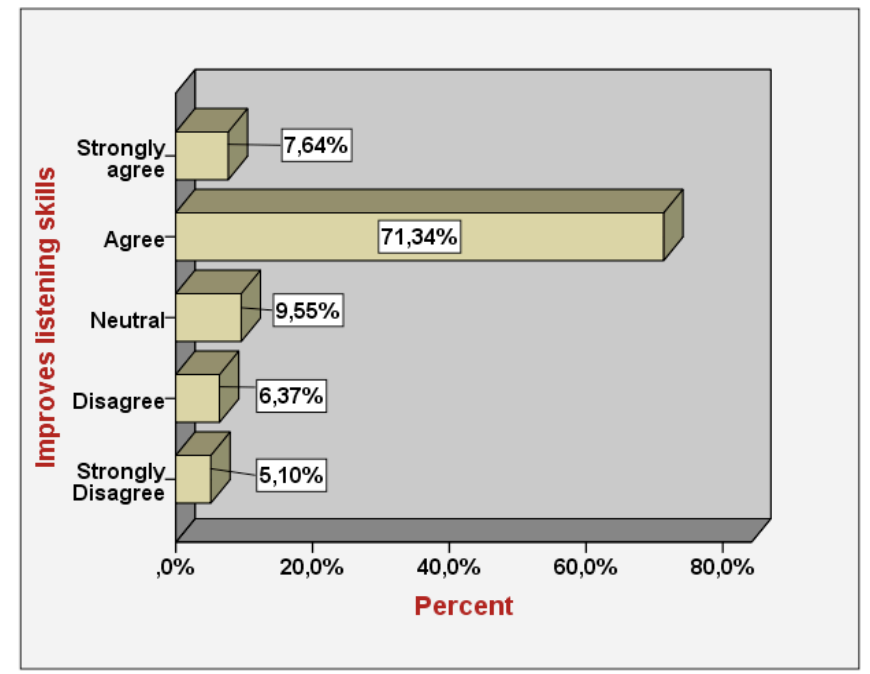

Fig. 10.. Does mobile learning improve listening skills?

11. Mobile learning as improving speaking skills: The majority of the learners $(76,43 \%)$ agreed that it improves speaking skills whereas $10,19 \%$ strongly agreed with $6,37 \%$ being neutral about it, $5,10 \%$ disagreeing and $1,91 \%$ strongly disagreeing (Fig.11)

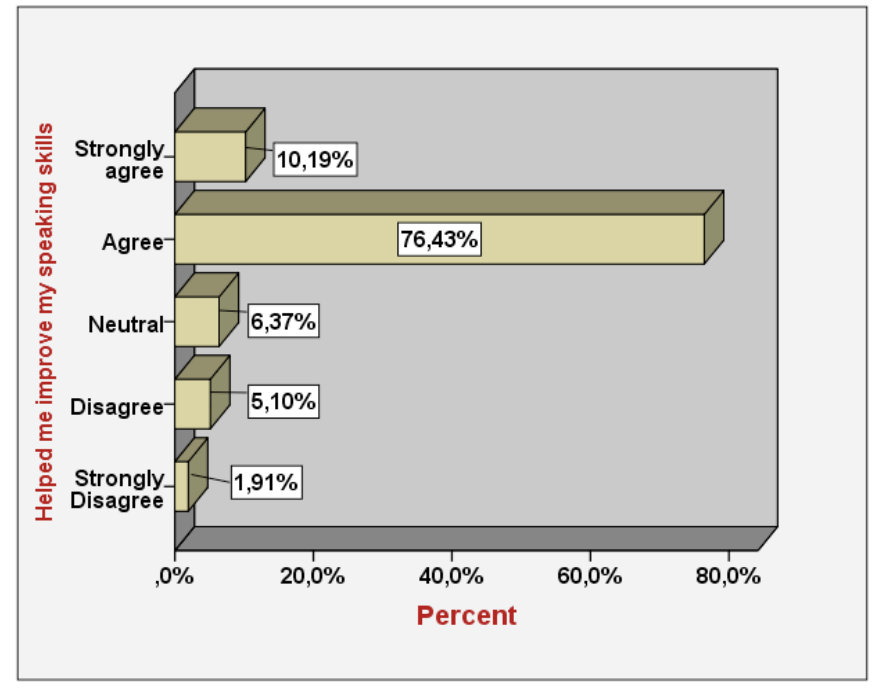

Fig. 11.. Does mobile learning improve speaking skills? 
12. Students working in parallel to their studies: There is a percentage of $14,01 \%$ of working students whereas the majority $85,99 \%$ of them only attended lessons without working (Fig.12).

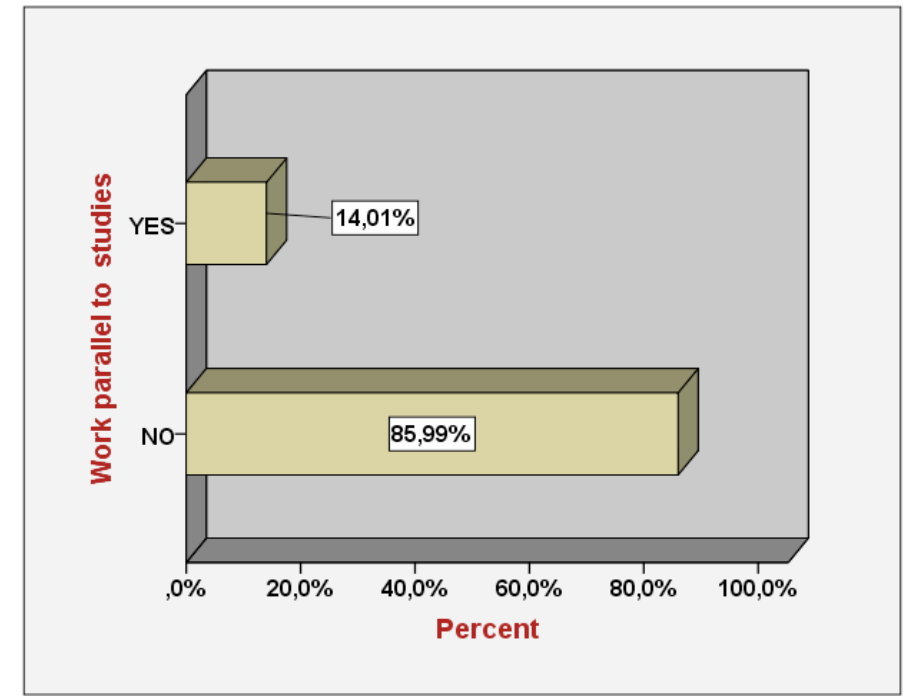

Fig. 12.. Does mobile learning improve speaking skills?

13. Mobile learning as being useful for working students: The majority of the working students $(81,82 \%)$ strongly agreed that it is useful whereas $13,64 \%$ of them agreed and 4,55\% remained neutral(Fig. 13 ).

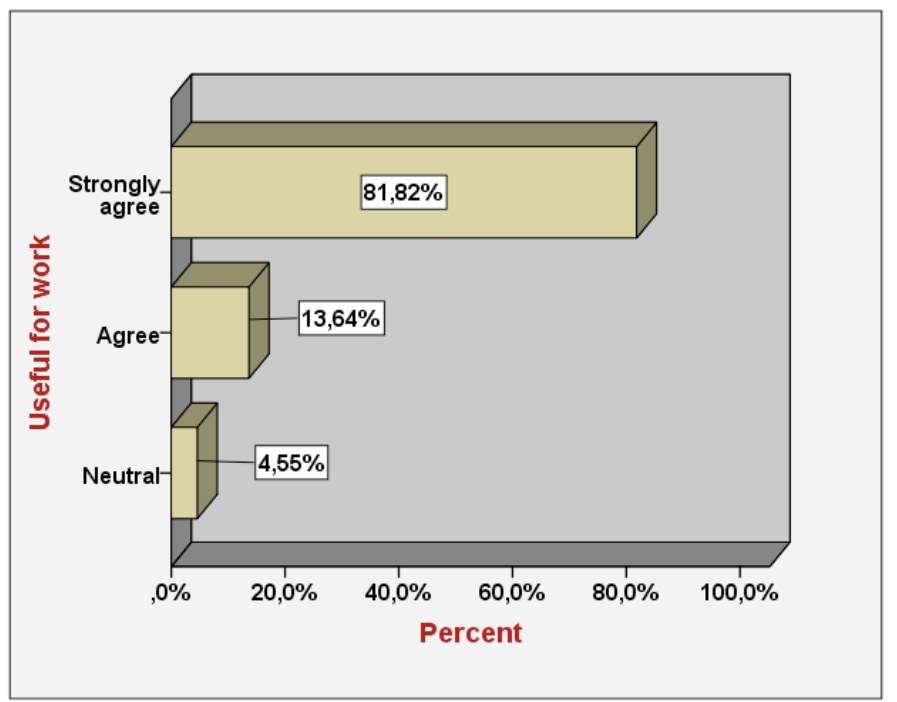

Fig. 13. Does mobile learning improve speaking skills? 


\section{Factors (Gender, Age, Work) that Affect the Students' Questionnaire Answers}

For the purposes of the analysis of this question the SPSS statistical package was used. The independent variables gender, age and work are categorized in two levels each: a. variable gender with two levels (1: Male, 2: Female), b. variable age with two levels $(1:<=18$ years, $2:>18$ years), c. variable working status with two levels (1: Students that work, 2: Students that don't work). The following table presents the results of the questionnaire analysis regarding the aforementioned factors (Table 1):

Table 1. How Gender, Age and Work Affect students opinion

\begin{tabular}{|l|c|c|c|c|c|c|}
\cline { 2 - 7 } \multicolumn{1}{c|}{} & \multicolumn{2}{|c|}{ GENDER } & \multicolumn{2}{c|}{ AGE } & \multicolumn{2}{c|}{ WORKING } \\
\hline Q1 & t-test & Con. & t-test & Con. & t-test- & Con. \\
\hline Q2 & $\mathrm{t}(155)=0,88, \mathrm{p}=0,380$ & No Sign & $\begin{array}{c}\mathrm{t}(155)=-0,71, \\
\mathrm{p}=0,477\end{array}$ & No Sign & $\begin{array}{c}\mathrm{t}(155)=-0,58, \\
\mathrm{p}=0,563\end{array}$ & No Sign \\
\hline Q3 & $\begin{array}{c}\mathrm{t}(155)=0,227, \\
\mathrm{p}=0,821\end{array}$ & No Sign & $\begin{array}{c}\mathrm{t}(155)=-1,036, \\
\mathrm{p}=0,302 \\
\mathrm{p}=0,014\end{array}$ & No Sign & $\begin{array}{c}\mathrm{t}(155)=-0,842, \\
\mathrm{p}=0,401\end{array}$ & No Sign \\
\hline Q4 & $\begin{array}{c}\mathrm{t}(155)=1,454, \\
\mathrm{p}=0,148\end{array}$ & No Sign & $\begin{array}{c}\mathrm{t}(155)=-9,029, \\
\mathrm{p}<0,001\end{array}$ & Sign & $\begin{array}{c}\mathrm{t}(155)=-6,727, \\
\mathrm{p}<0,001\end{array}$ & Sign \\
\hline Q6 & $\begin{array}{c}\mathrm{t}(155)=0,869, \mathrm{p}=0,386 \\
\mathrm{p}=0,041\end{array}$ & No Sign & $\begin{array}{c}\mathrm{t}(155)=-7,759, \\
\mathrm{p}<0,001\end{array}$ & Sign & $\begin{array}{c}\mathrm{t}(155)=- \\
7,073, \mathrm{p}<0,001\end{array}$ & Sign \\
\hline Q7 & $\begin{array}{c}\mathrm{t}(155)=0,426, \\
\mathrm{p}=0,671\end{array}$ & No Sign & $\begin{array}{c}\mathrm{t}(155)=-2,061, \\
\mathrm{p}=0,040 \\
\mathrm{p}=0,176\end{array}$ & Sign & $\begin{array}{c}\mathrm{t}(155)=-1,589, \\
\mathrm{p}=0,114\end{array}$ & No Sign \\
\hline Q8 & $\begin{array}{c}\mathrm{t}(155)=1,494, \\
\mathrm{p}=0,137\end{array}$ & No Sign & $\begin{array}{c}\mathrm{t}(155)=-5,873, \\
\mathrm{p}<0,001\end{array}$ & Sign & $\begin{array}{c}\mathrm{t}(155)=-6,718, \\
\mathrm{p}<0,001\end{array}$ & Sign \\
\hline Q9 & $\begin{array}{c}\mathrm{t}(155)=0,151, \\
\mathrm{p}=0,880\end{array}$ & No Sign & $\begin{array}{c}\mathrm{t}(155)=0,190, \\
\mathrm{p}=0,850\end{array}$ & No Sign & $\begin{array}{c}\mathrm{t}(155)=0,154, \mathrm{p}=0,8 \\
77\end{array}$ & No Sign \\
\hline Q10 & $\begin{array}{c}\mathrm{t}(155)=0,187, \\
\mathrm{p}=0,852\end{array}$ & No Sign & $\begin{array}{c}\mathrm{t}(155)=-2,102, \\
\mathrm{p}=0,037\end{array}$ & Sign & $\begin{array}{c}\mathrm{t}(155)=-1,702, \\
\mathrm{p}=0,091\end{array}$ & No Sign \\
\hline Q11 & $\begin{array}{c}\mathrm{t}(155)=0,556, \\
\mathrm{p}=0,380\end{array}$ & No Sign & $\begin{array}{c}\mathrm{t}(155)=-1,033, \\
\mathrm{p}=0,303\end{array}$ & No Sign & $\begin{array}{c}\mathrm{t}(155)=-0,840, \\
\mathrm{p}=0,402\end{array}$ & No Sign \\
\hline
\end{tabular}

Based on the above table results and as regards the factor "gender" it can be seen that there is no statistically significant result for any of the questions except question six. This means that the students' opinion regarding the method is not affected by their gender. However their opinion about the appropriateness of the method isaffected by their gender $(t(155)=2,056, p=0,041)$, with male students believing the method is appropriate to a bigger extent than the female students. Regarding the factor "age" it can be seen that there are statistically significant results for questions two $(\mathrm{t}(155)=$ $2,478, \mathrm{p}=0,014)$, four $(\mathrm{t}(155)=-9,029, \mathrm{p}<0,001)$, five $(\mathrm{t}(155)=-7,759, \mathrm{p}<0,001)$, seven $(\mathrm{t}(155)=-2,061, \mathrm{p}=0,040)$, eight $(\mathrm{t}(155)=-5,873, \mathrm{p}<0,001)$ and ten $(\mathrm{t}(155)=-2,102$, $\mathrm{p}=0,037)$. However, for questions one, three, six, nine and eleven there are no statistically significant results. This means that the students' age affects their opinion regard- 
ing characteristics of the method such as innovation, motivation, usefulness, vocabulary improvement, reading skills and listening skills improvement with older students ( $>18$ years of age) being the ones that outbalance the younger students. Finally, for the factor "work" we have statistically significant results in questions four $(\mathrm{t}(155)=$ $6,727, \mathrm{p}<0,001)$, five $(\mathrm{t}(155)=-7,073, \mathrm{p}<0,001)$, six $(\mathrm{t}(155)=-2,747, \mathrm{p}=0,007)$ and eight $(\mathrm{t}(155)=-6,718, \mathrm{p}<0,001)$.Nevertheless, the results for questions one, two, three, seven, nine, ten and eleven present no statistically significant results. The above findings mean that the working status of the students affects their views concerning the motivating features of the method, its usefulness, its appropriateness, and its ability to improve their vocabulary level.

\section{Students' Focus Groups Discussions Results}

Based on the students' answers, the mobile learning approach was considered to be an interesting process and an innovation. According to them, it was something they enjoyed and wanted to use. They argued that in the beginning they felt insecure about its effectiveness because they were not used to this mode of learning and were not sure how to handle it. However, as they explained they gradually became very confident and realized that it was an easy process to navigate into the lessons and download documents or videos from their phones/tablets. They admitted that they liked this independency of learning and the ability to have access to their class material either at work or at home alone when they needed to study, especially in case of absences or when they needed to revise something and understand it better.

Especially for those students that worked, mobile learning activities were considered very useful because they advised them at work and at the same time they practiced all the theoretical material they had learned at school. Nevertheless, as they stressed, the most important element of this innovation was the school net which the teachers had managed to create. As they explained, this net of common activities provided them with the opportunity to look at other schools' work, enrich their knowledge, and thus, facilitate their learning and expand on their skills. However, there were a couple of learners that complained that if one does not have a smart phone or mobile data the material cannot be accessed at work easily. Last, a couple of teenage learners said that their parents were not very happy to see them use the internet all the time. However, as they admitted, they enjoyed thisprocess "as much as downloading songs or videos" and they felt satisfied to see themselves improve in class.

The following extracts depict their views: "I was not sure at first what we were supposed to do... we all said this... what is she [the teacher] thinking? ... but.. great... I look at it many times... I now know the parts of the boot [trunk of the car] in English! ... I don't have to look at google translate every now and then ..." Kostas, "you get in [means the platform] and you see more staff [means language material]... I like this... it's all that I have missed... when I don't go [means to school]... I know what goes on... it helps us keep track of what the teacher says..." Andreas, "it's good to have the answers ready at work! I used to feel frustrated!... all I have to do is just 
read it... the videos help me too..., Mrs...[the teacher] gives many examples... I'm better at work I think...!" Panos, "we can read it again at home. I like this. Sometimes I don't pay attention in the class... [laughter] at home it's quiet, I listen to the tasks and I do them... and it helps me to see what the other schools have uploaded... they [means the teachers] do it every day, it's useful for us" Marina, "my mother grumbles all the time when she sees me[means being on the internet], she doesn't know... I tell her why...it's the school that I do it for... but I feel good... when Mrs... asks me things in the class I remember what I had watched on the video and I can answer... that feels good!!" Nena.

\section{Discussion and Conclusions}

In this paper we have looked into mobile learning. More specifically we have tried to investigate the reasons teachers use mobile devices in their teaching and how they do it. Additionally we examined the teachers' opinion on mobile learning as a teaching and learning method and the students' views about it. The research employed quantitative and qualitative research methods using triangulation with questionnaires, interviews and focus group discussions aiming to draw possible answers for the research questions. The findings have shown that the teachers created a net for educational purposes which they used in order to upload their lessons and ESP activities, available for all the ESP students. According to their answers their decision to use a mobile mode of learning was based on their wish to supplement the syllabus. Mainly however they wanted to address the linguistic diversity of the students and their gaps in knowledge due to distance problems, thus causing absences, but also out of personal curiosity to experiment on new methods adding variety to their teaching methodology, exploring new paths. The research has shown that the teachers have taken advantage of students' smart phones and/or tablets to design their scenarios with a variety of topics for a variety of specialisms: "Expanding vocabulary for car mechanics", "Filling in tax forms for accountants", "Instructions for refrigerants on the use of electrical appliances", "Preparing a report for computing employees", "Authentication - an easy process for insurance agents", "Helping a salesman to follow directions". The teachers argued that this was a motivating experience for the students who used thematerial having adequate time to clarify any vague points or questions at their own pace, thus, eliminating the fear of being ridiculed or devalued by "good" students in class. As they admitted mobile learning made a real difference in their methodology to such an extent that even specialism teachers expressed their wish to employ it in their teaching regardless of the fact that a minority of colleagues considered it a "game" as opposed to traditional teacher-centered teaching. As regards the students, their questionnaire answers revealed that the majority of them found mobile learning to be an easy $(74,43 \%)$, innovating $(83,44 \%)$, interesting $(77,71)$ and useful $(71,97)$ process to learning. It is worth mentioning that the majority of them believed that mobile learning helped them improve their vocabulary $(88,54 \%)$, reading $(84,08 \%)$, listening $(71,34 \%)$ and speaking $(76,43 \%)$ skills, whereas a percentage of $65,61 \%$ of the learners seemed to be neutral about the effect it had on the writing skills. Similar- 
ly, out of the $14,01 \%$ of the learners who worked in parallel to their studies a percentage of $81,82 \%$ of them considered mobile learning useful for their work. Moreover, according to the findings, the students' gender does not affect their opinion on the method but the male students seem to believe that the method is appropriate to a greater extent than the female learners. Our informal discussions with the students revealed that this is probably due to social reasons as male students feel the pressure to have some profession as "head of a family" more than girls do and therefore, they are interested in what can prepare them appropriately for their integration in the employment market. Similarly, the results have shown that older students believe that the method is innovative, motivating, useful, and helps them to improve their lexical, reading and listening skills more than the younger students. Through our conversations it was shown that older students seem to be more critical than the younger students because they want to link theory to practice. As the older students revealed, a teaching/learning method to them is important to motivate them in order to improve because there are age limitations and being older means they need to move on with their lives by looking for a job after school. Finally, the students that work think that the method was motivating, useful, appropriate and that improved their vocabulary skills to a bigger extent that the learners that didn't work. They justified this explaining that it is necessary for them to be efficient in their work due to competition in the market and admitted that this method gave them the tools they needed to maintain a good level at their work.

Last, according to the focus groups discussions results, students enjoyed the process, although they were quite dubious about its effectiveness at start. According to their answers, the creation of this net was the most interesting part of the mobile mode of learning as it helped them use it every time they needed advice. Especially for those working in parallel to their school studies, the mobile learning material was considered very useful because they used it at work when needed. Finally, some difficulties such as parents' complaints for an extensiveuse of the internet or lack of mobile data integrated in their mobiles did not seem to discourage them from making use of their mobile devices in order to download the learning material which they thought helped them improve their knowledge and skills, making them feel proud of themselves.

In the complex and challenging educational reality of today educators need to employ a variety of roles to cope with the difficulties they have to confront in schools daily. Their responsibilities increase and their roles seem to be multiple but they should always be centred on the students themselves. Perhaps the most important task they undertake is how to help them become autonomous learners and help them gain their self-confidence. For this to be realized all educational stakeholders (teachers, policy makers) need to emphasize learners' personalized needs. This may mean the adoption of a variety of methods and tools that will cater for everyone and will focus on ways to fulfil these needs. For, every student is valuable and every student is different with different aims, background knowledge and experiences. And it is only when these differences are respected that education may be successful and turn its attendants into the content, capable and promising citizens of today and tomorrow. 


\section{References}

[1] AskariArani, J.:The effect of ICT-based teaching method on medical students' ESP learning. Journal of Medical education, 4, 81-83, (2004)

[2] Korhonen, A., Malmi, L., Myllyselka, P., Scheinin, P.: Does it make a difference if students exercise on the web or in the classroom? In: Proceedings of The 7th Annual SIGCSE/SIGCUE Conference on Innovation and Technology in Computer Science Education, ITiCSE'02, Aarhus, Denmark, (2002) https://doi.org/10.1145/544414.544452

[3] Mumtaz, S.: Children's enjoyment and perception of computer use in the home and the school. Computers and Education, 36, 347-362, (2001) https://doi.org/10.1016/S03601315(01)00023-9

[4] Leone, S.: The use of new technologies in advanced Italian classes. Proceedings of the Emerging Technologies Conference, University of Wollongong, 18-21, (2008)

[5] Padurean, A., Margan, M.: Foreign Language Teaching Via ICT. Revista de Informatica Sociala, VII (12), 97-101, (2009)

[6] Crystal, D.: Language and the Internet, Cambridge: Cambridge University Press, (2001) https://doi.org/10.1017/CBO9781139164771

[7] M. Rahimi\& S. Yadollahi, ICT Use in EFL Classes: A Focus on EFL Teachers' Characteristics, World Journal of English Language, (October 2011) Vol. 1 (2), pp. 1729, (2006)

[8] L.Zhihong, H. Leijuan\& H.Xiaohui, A research on a student-centered teaching model in an ICT-based English audio-video speaking class, International Journal of Education and Development using Information and Communication Technology (IJEDICT), Vol. 6 (3), pp. 101-123, (2010)

[9] M. S. Gomez, Using web resources to support teachers and students with the teaching and practice of listening comprehension, Encuentro 19, pp. 2031, (2010)

[10] B. N. Bassma, The Impact of Using Technology in Teaching English as a Second Language, English Language and Literature Studies, Vol. 3 (1), 111-116, (2013)

[11] Dudley Evans, T., St John, M.: Developments in ESP. A multi-disciplinary approach. Cambridge: Cambridge Univeristy Press, (2001).

[12] Baker, A., Dede, C. \& Evans, J. The 8 Essentials for Mobile Learning; success in Education. QLIALCOMM, Wireless Reach, 1-39, file:///C:/Users/USER/Downloads/the-8essentials-for-mobile-learning-success-in-education.pdf

[13] http:/www.intel.com/content/www/us/en/education/k12/mobile-learning/_introduction/defining.html

[14] Koutroumani, O.:Mobile computational devices in pre-school age, Postgraduate diploma, Faculty of sciences, Department of mathematics, P.M.S. "Mathematics and contemporary applications", Sector of "Computational mathematics and computer science", Specialty "Technologies of computer science and communication in education", Patras, (2014)

[15] Amanatidis, N.: Mobile Learning, Learning through Mobile Devices, "Digital and Internet application in education", Proceedings of the $2^{\text {nd }}$ Panhellenic Educational Conference of Imathia, 23-15 April, Veria and Nousa, (2010)

[16] West, M.D.: Mobile Learning: Transforming Education, Engaging Students, and Improving Outcomes, Center for Technology Innovation at Brookings, http://www.brookings.edu /research/papers/2013/09/17-mobile-learning-education-engaging-students-west,(2013)

[17] Oller, R.: The Future of Mobile Learning, Educause, Center for Applied Research, https://net.educause.edu/ir/library/pdf /ERB1204.pdf, (2012)

[18] Manohar, S. Learning 3.0 Technology Implications on Pedagogy \& Learning Styles. Available at: http://www.emantras.com /Learning\%203\%200\%20Final.ppt 
[19] Tomlinson, C.A.: Differentiation of Instruction in the Elementary Grades, ERIC Digest, Eric Clearinghouse on Elementary and Early Childhood Education, (2000)

[20] L. Cohen \& L. Manion, Research methods in Education, Athens: Metehmio, (2000) https://doi.org/10.4324/9780203224342

\section{Authors}

Marianthi A. Batsila is a doctoral research student in the University of the U.K. She also works as a school advisor for the Greek Ministry of Education for both primary and secondary education, General and Vocational. Her research interests focus on ESP, mobile learning, ICTs in education and CLIL methodology in ELT. She has worked for secondary education for more than 30 years and has published a number of articles as well as presented her work in a number of conferences.

Charilaos A. Tsihouridis is a post-doctoral research student in the Department of Special Education, at University of Thessaly in Greece. His research interests lie on the field of ICTs and experimental physics. He has been working for Secondary Education for more than 30 years and has published an extensive number of articles on relevant issues and presented his research work in many conferences worldwide.

Anastasios, A. Tsihouridis is a University student in the department of Education at Democritus University. He is highly interested in the use of ICTs in education, gamification, and educational software in teaching students. He is also highly interested in the use of music therapy for students with learning difficulties.

Article submitted 21 November 2016. Published as resubmitted by the authors 23 February 2017. 